\title{
Radio y Redes sociales: la interactividad radiofónica en los 'Morning Shows' en España
}

\author{
$\mathrm{M}^{\mathrm{a}}$ de los Ángeles Alonso GonZÁLez \\ Universidad de Sevilla \\ malonsog@us.es
}

Recibido: 25 de marzo de 2014

Aceptado: 29 de septiembre de 2014

\begin{abstract}
Resumen
El perfil de la audiencia radiofónica ha cambiado en España y exige una participación más activa en un medio que se rinde ante la Cultura $2.0 \mathrm{y}$ en el que la interactividad se convierte en un elemento imprescindible. El presente estudio analiza los Morning Shows españoles y la actividad comunicativa que mantienen con sus oyentes gracias a las herramientas derivadas de la Web 2.0 a fin de correlacionar el share social y la audiencia real de los mismos. Los resultados alcanzados dibujan un escenario en el que los oyentes dejan de ser pasivos y se convierten en co-creadores del programa radiofónico.
\end{abstract}

Palabras clave: Radio, Morning Shows, redes sociales, Facebook, Twitter.

\section{Radio and Social Networking:}

The radio interactivity in Morning Shows in Spain

\begin{abstract}
The profile of the radio audience has changed in Spain and need for more active participation in media culture surrenders to 2.0 and in which interactivity becomes an essential element. This study analyzes the Spanish Morning Shows and activity maintained by tools derived from Web 2.0 to study whether social share correspond to your actual audience. The results obtained outline a scenario in which listeners are no longer passive and begin to become co-creators of the radio program.
\end{abstract}

Keywords: Radio, morning shows, social networking, Facebook, Twitter.

\section{Referencia normalizada}

ALONSO GONZÁLEZ, Ma de los Ángeles (2015): "Radio y Redes sociales: la interactividad radiofónica en los 'Morning Shows' en España”. Estudios sobre el Mensaje Periodístico. Vol. 21, Núm. 2 (juliodiciembre), págs.: 689-704. Madrid, Servicio de Publicaciones de la Universidad Complutense.

Sumario: 1. Introducción; 1.1. Programas despertador. 2. Objetivos y metodología; 2.1. Hipótesis. 3. Desarrollo y resultados; 3.1. Los programas; 3.2. Webs y Blogs; 3.3. Facebook y Twitter. 4. Conclusiones. 5. Referencias bibliográficas.

\section{Introducción}

Las herramientas derivadas de la Web 2.0 han transformado los escenarios tradicionales de interactividad grupal e individual y, por ende, han modificado la forma de hacer Periodismo. Si hace unos años diarios como Usa Today o Financial Times creían que su futuro estaba en convertirse en auténticas redes sociales para sus lectores, la radio no ha asistido al evento de forma indiferente y se ha sumado al fenómeno de la participación en Internet a través de la Web 2.0, recuperando de esta forma su espacio de conversación e interactuación con el oyente.

A lo largo de su historia la radio ha sufrido múltiples variaciones en su programación en un intento de acercarse a la realidad social de cada momento, por eso no es de extrañar que en medio del fenómeno de globalización en el que nos hallamos inmersos, la radio se ajuste a las nuevas formas de contar, atendiendo a las redes sociales y 
a los nuevos modelos expresivos a fin de construir un relato en el que la interactividad se convierte en un elemento imprescindible.

El perfil de los oyentes está cambiando. Las audiencias exigen una participación más activa a un medio que, tradicionalmente, ha sido interactivo y participativo, para ello la radio, como ya han hecho prensa y televisión, se rinde ante la Cultura 2.0 adquiriendo un nuevo matiz de bidireccionalidad, ya que no sólo ofrece contenidos, sino que escucha a sus oyentes, sus demandas y necesidades para ofrecerles aquello que buscan, creando posibilidades de consumo diferentes y definidas según criterios personales. Nuevos contenido que, como afirma Ortiz Sobrino "implican nuevos protocolos e interacción que superen los esquemas clásicos para llegar a usuarios activos con capacidad de buscar, intercambiar y de producir contenidos radiofónicos que enriquezcan y condicionen el discurso radiofónico" (Ortiz: 2011).

Los flujos y las actitudes de la comunicación están cambiando. La universalización de la posibilidad de ser emisor de mensajes que lleguen a grupos numerosos a través de Internet ha provocado la ruptura del esquema tradicional de comunicación lineal y su sustitución por otros modelos circulares en los que cualquier individuo puede ser receptor y emisor a la vez, lo que está conduciendo a los medios a cambiar su actitud con la audiencia del discurso al diálogo (Túñez, Solana y Abejón: 2010).

Esta interactividad con el oyente ha sido siempre la seña de identidad de la radio, la cual aporta inmediatez y feedback frente a otros medios de comunicación. Desde sus orígenes, el medio radiofónico ha estado siempre en constante cambio, de hecho la urgencia en la retransmisión de las noticias forzó la creación de un nuevo estilo periodístico basado en la introducción del directo y en la posibilidad de mantener un diálogo simultáneo con los corresponsales.

Con la aparición de la televisión, la radio comienza a perder audiencia y es entonces, en la década de los años 50, cuando se replantea una nueva forma de hacer Periodismo que le viene propiciada por la incorporación de nuevos avances tecnológicos y por la incorporación en los 60 de la música Pop a su programación.

Si bien la actualidad se perfila como la constante radiofónica, en la década de los 70 los micrófonos salen a la calle para darle voz a los oyentes al tiempo que se introducen nuevas visiones, conceptos y modos de decir con una narrativa más fresca y próxima al oyente que encuentra su máximo exponente durante los años 80 . De hecho, como afirma Peña Jiménez, "sus potencialidades introdujeron frescura en la radio, permitiendo y generalizando todo tipo de intervenciones formuladas tanto en directo como en diferido". (Peña: 2013:231)

El fin de monopolio de $R N E$ y la concesión de 120 nuevas licencias a empresas como Antena 3, Radio 80, SER, y COPE, convierten a la radio en España en un medio ágil y dinámico que entrevista a los protagonistas de las noticias. Surgen las tertulias, se generalizan los magazines y aparece un nuevo formato que enseguida capta la atención de la juventud española, la radiofórmula de la mano de Los 40 principales; un programa que entonces segmentaba cada bloque horario en espacios de distinta evaluación musical y comercial, según los contratos de las emisoras con las casas discográficas (Balsebre, 2002: 465).

La popularización de Internet a partir del año 1995, se encarga de que la evolución mediática de los mass media tradicionales vaya "ampliado su cobertura en el entorno 
digital con nuevos modelos comunicativos" (Castelló Martínez, 2010: 42) y la radio comienza apostar por una nueva forma de presentar la programación mediante la publicación en blogs, dominios de Internet y redes sociales que completan el sonido con las características propias del hipertexto. Es decir, se comienza a combinar el audio con elementos textuales e imágenes, al igual que ocurre con el resto de los cibermedios.

El grado de penetración de las redes sociales en nuestra sociedad es cada vez mayor y una tendencia imparable, gracias, en gran medida, al uso de los smartphones, los cuales permiten estar conectados a cualquier hora y en cualquier lugar. De hecho, Internet se posiciona como el gran protagonista del tercer acumulado del Estudio General de Medios.

La red de redes alcanza ya un 53,7\% de penetración, un 7\% más que en el tercer acumulado de 2012. 25,3 millones de españoles se conectaron a Internet a lo largo del último mes de febrero, un $6,5 \%$ más que el año pasado. El acceso a Internet a través de móvil se ha duplicado en el último año, se ha triplicado a través de las tablets y se ha multiplicado por cinco a través de la televisión conectada. Respecto a las actividades realizadas a través de Internet, el uso de mensajería instantánea aumenta un $62 \%$, los juegos online crecen un $41 \%$ y la conexión a redes sociales se incrementa un $13 \%$.

La proliferación del uso de dispositivos móviles permite, además, la obtención de datos como que el $75 \%$ de los españoles entra en Internet todos los días, el 24\% de las conexiones se realiza desde la calle o el transporte público y que la inmensa mayoría de las mismas son para acceder a las redes sociales (68\%), siendo Facebook la que ostenta el liderazgo absoluto (90\%), seguido de incremento en casi 14 puntos de Twitter (37\%), la cual llega a superar, incluso, a Tuenti (25\%). (AIMC: 2013)

Otros datos significativos que se desprenden de este estudio es un alto nivel de participación por parte de los internautas en la creación de contenidos de las webs. De hecho, el $58 \%$ sube fotos y el $40 \%$ colabora con textos, al tiempo que el $68 \%$ lo hace con contenidos multimedia, el $45,6 \%$ ve, escucha y lee contenidos sin descargarlos y sin comentarlos o etiquetarlos, mientras que el $32,5 \%$ etiqueta y añade comentarios a los contenidos. A todo ello ha contribuido el uso generalizado de YouTube y las nuevas fórmulas de participación ciudadana que los diarios online han puesto en uso.

Dentro de este contexto, las redes sociales, principalmente Facebook y Twitter, se erigen en herramientas que permiten modificar los procesos de creación, edición, distribución y consumo de contenidos de todo tipo, hasta el punto de ser uno de los ejes vertebradores del consumo digital en España.

Facebook lidera cada vez con mas fuerza el espacio social digital con una combinación de intereses personales, profesionales y de contenido. En tan solo diez años ha llegado a tener 1.200.000 millones de usuarios activos. En España continúa imbatible entre los internautas, aumentado su ventaja y consolidándose como uno de los grandes motores de tráfico de información.

Según el informe enviado por Facebook a sus socios europeos y recogido por Tech$\mathrm{Crunch}^{1}$, la red social posee 12 millones de usuarios españoles diarios y 18 millones

${ }^{1}$ Publicación web en formato blog que trata principalmente sobre iniciativas empresariales, productos y sitios web. Fue fundado por Michael Arrington en 2005. El primer post del blog fue creado el 11 de junio de 2005. 
de usuarios mensuales, lo que significa que el $58 \%$ de los usuarios españoles de Internet están en esta plataforma. Además, tiene 8,1 millones de usuarios móviles diarios y 13 millones de usuarios móviles mensuales, cifras que suponen el 32\% de los usuarios móviles de España.

Creado en 2006, Twitter se ha convertido en una plataforma planetaria con más de 500 millones de usuarios, de los cuales 241 son mensuales, es decir, que se han conectado al menos una vez en los últimos 30 días. España es el segundo país europeo y el octavo a nivel mundial con el mayor número de usuarios activos en la plataforma del pajarito. Con una tasa de penetración del 36,9\% entre los internautas, supera la barrera de los cinco millones de miembros, de los cuales el $63 \%$ accede a diario y el $80 \%$ lo hace a través de dispositivos móviles, según datos dados a conocer durante la primera jornada del Mobile World Congress 2014.

\subsection{Programas despertador}

La radio es información y comunicación. Cada emisora tiene una intencionalidad comunicativa y expresiva sobre la que idea su estrategia de programación. Si bien la radio generalista podría definirse como radio-información-comunicación y está dirigida a todo tipo de público, la radio especializada se distingue por ofrecer un producto radiofónico exclusivo en el mercado para apelar de forma más directa a un target, que se muestra como el público más objetivo para el anunciante.

Tanto las radios como sus modelos de programación han generado dos narrativas radiofónicas principales: la ideada sobre el concepto de programa y la basada en el concepto de fórmula. El programa y la fórmula son las dos unidades principales de toda programación. Dichas unidades se refieren tanto a la selección del contenido como a su duración. A estas narrativas puede añadirse una tercera de carácter mixto. Éstas se diferencian en el modo de idear y estructurar el relato radiofónico que es toda programación.

A medio camino entre la radio musical y la radio convencional encontramos los Morning Shows, una fórmula que recoge elementos de ambos formatos y los adapta al target de sus oyentes, los cuales oscilan entre los 14 y los 35 años. Contenidos inteligentes y oportunos, dosis de humor, bromas telefónicas y un punto de actualidad son los ingredientes que ofrecen este tipo de programas como contrapunto a la seriedad informativa de la radio convencional, al tiempo que se convierte en el camino natural que sigue la audiencia más joven para adentrarse en la radio con contenido.

Si bien en la televisión el share social de programas y cadenas se ha convertido en un análisis diario habitual junto a las audiencias tradicionales, de forma que los espectadores pueden demostrar a través de las redes sociales sus preferencias por los programas que están viendo en la pequeña pantalla, en el caso de la radio no existen medidores reales de esta cultura participativa de abajo hacia arriba, como la define Henry Jenkins, y que pone de manifiesto que existe un nuevo espectador social capaz de convertirse en parte integrante del mensaje gracias a su participación activa en plataformas de redes sociales.

En este sentido Blanco Pont manifiesta que en la mayoría de los espacios informativos se ha producido una reestructuración de los equipos humanos disponibles, "no ya para generar contenidos, sino para distribuirlos y adaptarlos a esa apuesta por estar presentes en la red y por promover la interactividad con la audiencia". En este 
sentido, afirma que "las figuras de los gestores de contenido han ganado importancia aunque su papel no se considere tan importante como el de aquellos que proyectan su voz ante el micrófono" (Blanco, 2013: 216).

La empresa de radio muestra hoy un especial interés por estar presente en la Web 2.0, de hecho, todas las cadenas radiofónicas españolas tienen presencia en al menos una de las redes sociales que mayor número de seguidores tienen en nuestro país.

A fin de estudiar la presencia y actividad que los oyentes presentan en las redes sociales, hemos decidido analizar la actividad comunicativa que mantienen los Morning Shows españoles con sus audiencias, ya que si hay un formato dentro de la radio que más enganche al segmento joven y, por ende, genere una mayor presencia en Internet ese es sin duda el formado por los denominados "programas despertadores", un formato que triunfa en nuestro país, tal y como evidencia el hecho de que existan hasta diez programas diferentes que se reparten a diario casi seis millones de oyentes, provocando, incluso una sobreoferta y saturación que se traduce en las fuertes caídas experimentadas en el último EGM.

Según la última Encuesta General de Medios, en el ámbito de los Morning Shows el liderazgo lo posee "Anda ya!" de Los 40 Principales, con 1.624 .000 oyentes y un retroceso de 68.000 seguidores. Le sigue “¡Buenos días Javi Nieves”, en Cadena 100, con 1.082.000 seguidores y un retroceso de 33.000 oyentes. El tercer puesto lo ocupa "Atrévete" de Cadena Dial con un millón de audiencia y una pérdida de 14.000, seguidos de "Levántate y Cárdenas", de Europa FM y 984.000, 110.000 menos que en la anterior oleada.

El quinto puesto es para "El pirata y su banda" de Rock FM con 396.000 seguidores y un alza de 49.000 espectadores, "La mañana de Kiss FM", con 383.000 personas y un crecimiento de 40.000 oyentes; "El Gallo máximo" de Máxima FM con 259.000 seguidores y 93.000 oyentes menos; y "Morning 80 " de M80 con 231.000 seguidores y una pérdida de 107.000 adeptos.

Cierran la lista "El ahitador" de Hit FM, en antena desde el 25 de noviembre de 2013, y "Lo mejor que te puede pasar" que, capitaneado por Nuria Roca, llegó a Melodía FM el 9 de enero de 2014 para relanzar las mañanas del grupo Atresmedia.

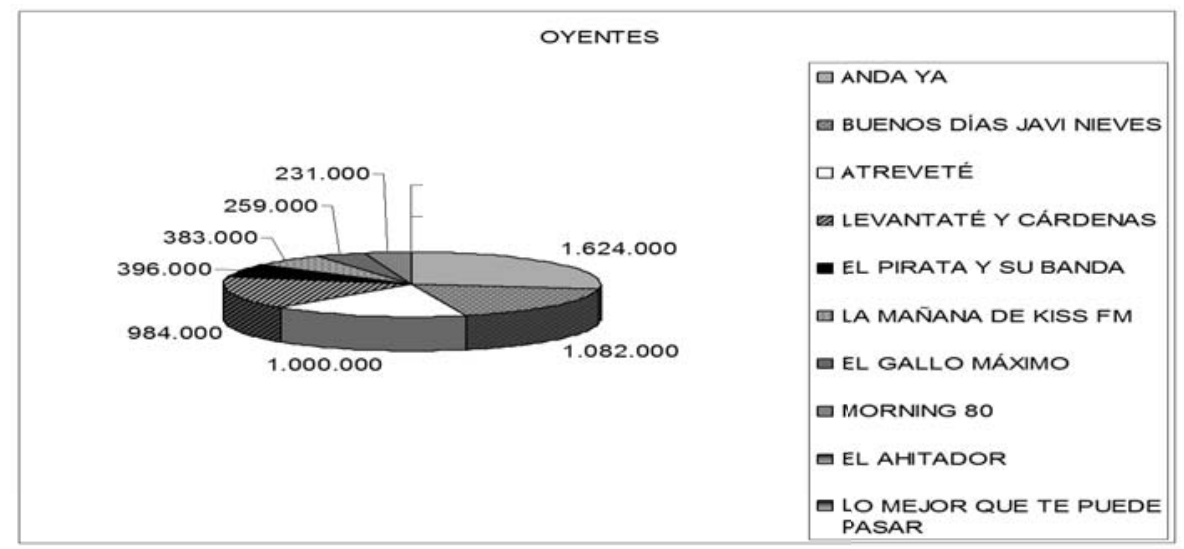

Elaboración propia 


\section{Objetivos y metodología}

El método de trabajo elegido para la aproximación al problema de investigación combina técnicas de carácter cualitativo y cuantitativo, amén de una revisión de la literatura sobre el tema de las redes sociales y su efecto sobre el Periodismo.

Junto a la imprescindible revisión bibliográfica que toda investigación requiere, para el seguimiento de este estudio hemos realizado un trabajo de carácter exploratorio de rastreo y seguimiento de los diez Mornings Shows actualmente en antena y su presencia en las redes sociales Facebook y Twitter, prestando especial atención a la oferta comunicativa que ofrecen de forma complementaria las páginas personales de dichos programas: blogs, webs, redes sociales, correos electrónicos, teléfonos y direcciones postales.

También hemos realizado un análisis del contenido de las publicaciones para intentar determinar el tono del lenguaje (formal o informal), flujos de comunicación (ascendente o descendente), la interactividad (baja, media o alta) y el tipo de contenido (temáticas de las publicaciones).

El método responde pues a una combinación de técnicas cuantitativas y cualitativas que conceden mayor rigurosidad y valor a la investigación ya que ambas se complementan y refuerzan. En este sentido, hemos tenido en cuenta que la opinión de la audiencia es una de las mejores maneras de hacer un análisis cuantitativo del producto radiofónico para compararlo después con los datos aportados por el EGM y comprobar, si Internet, en general, y las redes sociales, en particular, están tan integrados en nuestro día a día hasta el punto de poder llegar a influir en nuestras decisiones y contribuir a crear una radio activa en la que el oyente puede participar de manera simultánea.

Para ello atenderemos a criterios cualitativos (potencial comunicativo) y cuantitativos (número de usuarios), ya que se tratan de las dos redes sociales más generalistas y populares en todo el mundo. De hecho, según datos de enero de 2014, Facebook reportaba mil millones de usuarios activos que comparten cada día un total de $2,5 \mathrm{mi}-$ llones de piezas de contenidos, mientras que Twitter registraba 560 millones de usuarios activos que publican un total de 5.700 tuits por segundo. (Mediabistro, 2014).

En España, según el medidor externo, Adexa.com, Facebook ocupa el tercer lugar en el ranking de webs con mayor audiencia del planeta, superada únicamente por Google.es y com. Twitter, por su parte, ocupa el sexto lugar, por detrás de YouTube y Live.com

Cada red social tiene sus propias pautas y normas de comportamiento, pero en líneas generales, tanto Facebook como Twitter, cada usuario establece un espacio virtual de comunicación interpersonal y colectivo que no tiene por qué coincidir temporalmente en la acción, ofrece un punto virtual de reunión en el que la invitación a entrar es permanente y en el que el contenido llega al usuario sin necesidad de que este lo busque, de forma que los contenidos adquieren un importante matiz de proactividad.

Otras características comunes que presentan ambas redes sociales y que hemos considerado como clave a la hora de elegirlas es una vigencia limitada del mensaje y una comunicación dialógica cuyas aportaciones se ciñen a los criterios de brevedad y concisión, y en el que prima la jerarquización de contenidos para que el receptor lo tenga todo a simple vista. 


\subsection{Hipótesis}

Nuestra hipótesis de partida se basa en que la nueva audiencia social se ha convertido en catalizador del cambio de hábitos en el consumo radiofónico, de manera que los ciudadanos han dejado de ser un mero consumidor de contenidos para participar en la construcción y elaboración de los mismos.

Este fenómeno se está produciendo en la radio de forma incipiente y, por este motivo, existen numerosos sectores que reclaman medidores de share social que complementen los datos aportados por el EGM. Es por ello que a lo largo de esta investigación pretendemos estudiar la forma en que los nuevos oyentes de la radio se relacionan con el medio y están modificando la forma tradicional de hacer radio en España a través de las herramientas derivadas de la Web 2.0.

Puesto que la mayoría de los usuarios de las redes sociales en España son jóvenes con edades comprendidas entre los 18 y los 39 años (casi el 69\%), según el último estudio de IAB Spain Research ${ }^{2}$, y puesto que este target coincide con los oyentes de los Morning Shows de la radio española, vamos a estudiar cómo dichos programas radiofónicos usan las redes sociales, con qué frecuencia, si interactúan con sus audiencias o si toman decisiones a partir de los comentarios que los oyentes les dejan en ellas.

En base a nuestra hipótesis de partida y las preguntas que nos formulamos hemos definido un objetivo general que es identificar la presencia de los Mornings Shows de la radio española en las redes sociales Facebook y Twitter, principalmente, y ver si Internet modifica la forma tradicional de hacer radio en España hasta el punto de poder hablar de una cultura participativa que transforma la sociedad en la que vivimos, pero también el tipo de relación que tenemos con los medios de comunicación y su consumo.

\section{Desarrollo y resultados}

El objetivo de todo medio es comunicar, y por ello, las redes sociales se presentan ante la radio como una gran aliada en la recuperación de un entorno que le era propio: la conversación. Gracias a la Web 2.0 la radio vuelve a su punto inicial pero experimentando nuevas formas de contar en las que la interacción con la audiencia cobra especial protagonismo.

El perfil del oyente-usuario ha cambiado y exige la participación activa en un medio que tradicionalmente ha sido interactivo y participativo, y esto precisamente es lo que explica que los diez programas de nuestro estudio tengan una mayor o menor presencia en Internet, principalmente a través de webs, blogs y de las redes sociales Facebook y Twitter.

De hecho, como afirma Josep María Blanco, no estar en Internet y no emplear las mismas herramientas que los oyentes utilizan habitualmente para comunicarse entre sí en las diferentes redes sociales puede castigar duramente la imagen de un medio y afectar a su estabilidad y supervivencia (Blanco, 2013: 213).

2 Asociación que representa al sector de la publicidad en medios digitales en España. 
La dura competencia entre medios ha llevado a la radio a flirtear definitivamente con el multimedia en España y "a intentar sacar provecho de la interactividad que proporcionan las nuevas tecnologías de la información y la comunicación, los new media y las redes sociales", continúa Blanco, y es por ello que los diez programas despertador objeto de nuestro estudio tienen presencia en una u otra red social, siendo la más utilizada Facebook (solo "Lo mejor que te puede pasar" no tiene perfil), mientras que solo tres de los diez programas mencionados no están logados en Twitter, a la razón: "Buenos días Javi Nieves", "E1 Pirata y su banda" y "Morning 80".

Un primer análisis de sus perfiles permite constatar que salvo los programas con una mayor audiencia la presencia del resto en el universo web es meramente testimonial, con escasas aportaciones diarias y una proactividad prácticamente nula.

\subsection{Los programas}

Los diez programas analizados se encuadran dentro de la categoría de "programa despertador" y se emiten de lunes a viernes de 6 a 10 de la mañana, salvo los dos correspondientes a la Cadena SER ("Anda Ya" y "Atrévete", que también poseen una edición especial los sábados en horario de 7 a 10).

Sus públicos objetivos oscilan en la horquilla de los 25 a 34 años, según ellos mismos indican en sus perfiles de Facebook y, por este motivo, suelen estar presentados por gente joven que se rodea de un nutrido grupo de colaboradores de primer orden que imprimen al programa ritmo y dinamismo.

Todos ellos destacan por su rico contenido informativo, humorístico y musical, un formato en el que se combina la música más actual con las noticias y otras curiosidades, así como sketches y bromas telefónicas que confieren al espacio un tono divertido y desenfadado.

Tal es el éxito de esta fórmula que muchos de los programas analizados han ganado un Premio Ondas, es el caso de "El gallo Máximo", de Máxima FM que lo obtenía en 2011 como "Mejor programa de radio"; "Anda Ya", de Los 40, con un Ondas a la Innovación Radiofónica, el mismo que obtuvo el presentador de "Levántate y Cárdenas", Javier Cárdenas, Premio Ondas a la "Innovación Radiofónica" por combinar información, humor y entretenimiento, organizando un crucero en el que durante un fin de semana se realizó radio en vivo, con actuaciones musicales y concursos, con la participación en directo de los oyentes, y propiciando de esta forma la convivencia de los comunicadores y artistas con la audiencia.

\subsection{Webs y Blogs}

En este apartado hemos estudiado las estrategias de comunicación on-line de cada uno de los programas anteriormente mencionados, determinando los contenidos e innovaciones que ofertan, bien a través de su web o blog.

En líneas generales tanto la autoría como el diseño de los blogs son corporativos y aportan una gran importancia a la figura del locutor que permite patrocinar el programa e incrementar el número de oyentes. Casi todos presentan un diseño basado en dos columnas, excepto "La mañana de Kiss FM" y "Lo mejor que te puede pasar", diseñado a tres columnas, y "El Ahitador", que no es más que un pop-up con información básica del programa y links a las redes sociales. 
El diseño suele ser atractivo y muy sencillo, respetando los colores corporativos de la cadena y del programa en cuestión. La portada suele funcionar a modo de home del sitio, combinando fotografías, vídeos y textos. La columna de la izquierda se organiza de forma similar a un índice, mientras que la de la derecha suele dedicarse a la publicidad y contiene las herramientas necesarias para hacerse seguidor en Facebook o Twitter y seguir los comentarios de los oyentes.

Inicio, equipo y concursos son secciones fijas que aparecen en todas las webs y blogs de los Morning Shows españoles, también en la mayoría encontramos enlaces a audios y vídeos, sobre todo de las bromas telefónicas que se realizan en el programa.

Atendiendo a criterios de contenido e interactividad con el oyente podemos hacer la siguiente división:

De entre todos los sites de los programas despertador destacan por su especial sencillez y escaso contenido "Buenos días Javi Nieves", "El Pirata y su banda", "Morning 80" y "El Ahitador", programas que ocupan los puestos segundo, quinto, octavo y noveno en el índice de audiencias del EGM. Se trata de webs icónicas principalmente, con poca actividad y escasa interactividad, en las que apenas se puede obtener información del programa o datos de contacto.

Así pues, en "Buenos días Javi Nieves", encontramos una web bastante plana con los datos de contacto del programa de forma bastante clara (teléfono gratuito, e-mail de contacto y de "Quién te tienta a las 9.30" y el Facebook) y enlaces para escuchar el programa completo, podcast de los mejores momento y de "Los Niños y Jimeno" y un formulario para convertirse en "Los compañeros del día".

En "Morning 80", sólo nos ofrecen el link a Facebook y un formulario de contacto. En "El Ahitador", podemos enlazar con el Twitter del programa (@elahitador) y de los dos presentadores: Jesús Taltavull (@jesustaltavul) y Beatriz García Alcázar (@beatrizgalcalzar)."El Pirata y su banda" nos ofrece un e-mail, teléfono y un link a Facebook, en cuanto a contenido solo podemos acceder a un podcast con lo mejor o escuchar las canciones de "El Canto del Broco".

En la zona media de información e interactividad con el oyente, encontramos programas como "La mañana de Kiss FM" o "Lo Mejor que te puede pasar". Ambos, pese a ser programas de reciente creación y tener poca audiencia, presentan una web en la que se aprecia el esfuerzo constante por mantener actualizada la información diaria y correspondiente al programa emitido. En ellas podemos encontrar datos del equipo, sobre secciones y concursos, resúmenes, audios, vídeos, fotografías e incluso información relativa a los colaboradores.

Mucho más completa es la web de Kiss FM, ya que en ella también se nos ofrece un teléfono de contacto, e-mail, así como links al Twitter del programa (@lasmananaskiss), de la presentadora (@crisLasvignes) y de sus colaboradores (@alfredoarense y@Marta_Ferrer), los cuales hacen menciones en sus cuentas personales sobre el Twitter del programa. En la web de "Lo mejor que te puede pasar" sólo encontramos un link a Twitter y Facebook de la cadena Melodía FM.

Los cuatro programas que encabezan el ranking de audiencia, excepto el número dos, "Buenos días Javi Nieves", y que se reparten casi cuatro de los seis millones de audiencia de los Morning Show españoles son los que presentan una web o blog con 
mayores referencias sobre el contenido de la radiofórmula y de los temas diarios, así como cuestiones de interés para la audiencia que les permiten situarse en la página de una forma más rápida. Dos de ellos pertenecen a la cadena SER ("Anda Ya" y "Atrévete"), por su parte, "Levántate y Cárdenas" es de Europa FM y "El Gallo Máximo" de Máxima FM.

Todos ellos utilizan un lenguaje informal a la hora de comunicarse con una audiencia que se caracteriza por tener un perfil joven. Este perfil condiciona el tipo de temática a tratar por los programas, cuyos temas de interés suelen estar orientados a un target poblacional de entre 20 y 35 años con un nivel medio de formación a los que les gustan los contenidos virales y los temás de interés general, que buscan estar informados de lo que ocurre en el mundo y para los que viajes, vídeos y fotografías suelen ser sus principales aficiones para sus momentos de ocio.

En este sentido, es menester aclarar que la comunicación suele ser bidireccional, con gran profusión en el ámbito de la comunicación ascendente y descendente, ya que las herramientas derivada de la Web 2.0 otorgan grandes posibilidades comunicativas a las audiencias, las cuales comentan de forma prolífica las entradas que el webmaster del programa introduce en la web.

Los contenidos del programa son actualizados a diario, incorporando una media de cinco entradas diarias que se corresponden con los hitos más importantes que han tenido lugar durante la emisión del mismo. De igual forma, ofrecen enlaces a las páginas webs de la cadena e invitan a los oyentes a seguirlos en Facebook, de hecho, en la columna de la derecha suelen incorporar un listado con las últimas entradas de su muro, publicaciones que, en la mayoría de los casos se corresponden con las entradas del $b \log$.

Otros elementos comunes que podemos apreciar son que todas incluyen información sobre los profesionales que realizan el programa, fotografías y comentarios que cada colaborador expone a modo de saludo, así como sus Twitters personales.

De igual forma, todos ellos ofrecen a sus oyentes la posibilidad de contactar con el programa a través del teléfono y del correo electrónico. Entre todos ellos, sólo "Levántate y Cárdenas", va más allá y ofrece un WhatsApp (688.85.91.74). También existe la posibilidad de enviar comentarios sobre las noticias publicadas, solicitar bromas telefónicas y dejar mensajes en el contestador automático para que en programas sucesivos sean emitidos en antena.

Otra característica común que encontramos en estos cuatro programas es la posibilidad de enlazar con las redes sociales Google+, Tuenti, Twitter, YouTube, Pinterest, Instagram y Facebook, así como nubes de Tags que contienen palabras claves que describen el contenido de las historial, simplificando de esta forma la búsqueda, y fuentes RSS, enlaces a los archivos metadatos del blog que permiten sindicar el sitio y acceder a las historias más recientes mediante un lector de servicios de redifusión.

Por último, comentar que en todos ellos podemos hallar enlaces a audios, vídeos, concursos, así como un nutrido recopilatorio de bromas realizadas a lo largo del programa. De esta forma se busca un contacto más directo con la audiencia a la que constantemente se le remite desde el directo a volver a oír determinadas partes del programa en la web. 
La presencia de vídeos refuerza la iconicidad a la que nos tiene acostumbrada la televisión, le ponemos cara a la voz de las mañanas y podemos ver cómo se comportan en el estudio radiofónico durante la emisión del Morning Show, construyendo, de esta forma, un periodismo de proximidad que se completa gracias a la puesta a disposición de los oyentes de contenidos a la carta mediante diferentes tecnologías (podcast, streaming, repositorios, etc.).

La presencia en las webs y blogs de podcast o audioblogs configuran lo que Sergio Alguacil denomina radio on demand, es decir, que "cualquier persona puede consumir justo lo que ella quiere, a la hora que ella quiere, dónde ella quiere y en el formato que ella elige; pero, esto, desde un punto de vista mucho más convencional, a veces puede fomentar una comunicación un poco «egocéntrica»" (Alguacil, 2011:39).

A través de los podcast es posible distribuir contenidos audiovisuales asociados a sistemas de redifusión, garantizando la descarga de contenidos sonoros para su consumo bajo demanda en cualquier momento y dispositivo. Este modelo de difusión ha supuesto una "auténtica revolución en los hábitos de consumo del discurso sonoro", según Gerrudix Barrio, ya que en tan solo siete años, "la oferta de podcast en la Red ha crecido de forma exponencial tanto en cantidad como en diversidad de contenidos, abriendo un abanico amplio de géneros, categorías y temas".

A todo ello ha contribuido, de manera evidente, el despegue tecnológico de los dispositivos móviles lectores tales como el iPod, el Mp3 o el Mp4, y en última instancia las tablets y smartphones, aunque también es habitual su escucha en los ordenadores personales a través de software como iTunes o My Yahoo!.

\subsection{Facebook y Twitter}

La convergencia entre Radio e Internet ha cambiado la antigua relación entre emisora y audiencia, ya que permite al oyente volverse participativo y activo, porque opina y deja constancia de sus gustos, elige el lugar y la hora de escucha, al tiempo que genera contenidos al interactuar con los programas. Además, ahonda aún mas en la radio como un medio individual y móvil, alejándose de aquellos tiempos en que era un medio escuchado colectivamente.

Esta cualidad se potencia especialmente gracias al uso de las redes sociales, las cuales se convierten en sustitutos de foros y chats y se integran, como "un elemento más del perfil del oyente y de la identidad digital de la empresa", tal y como afirma Elvira Calvo.

A través de las redes sociales, principalmente, Facebook y Twitter, la mayoría de los Morning Shows de España ofrecen al radioyente la posibilidad de participar e interactuar en la comunicación radiofónica, ya que son frecuentes las menciones en directo a los comentarios que sobre la marcha van llegando al programa.

En este sentido estaríamos ante un panorama comunicativo en el que el consumidor de radio se suma al proceso de elaboración de los contenidos y al diseño de la programación, lo que Cebrián denomina "prosumidor".

La incorporación del uso de las redes sociales al formato radiofónico permite lo que Martínez Zarandona denomina "relaciones horizontales y democráticas donde todos puedan expresarse y elegir libre y reflexivamente sus gustos y preferencias, ejerciendo una recepción crítica". 
Un estudio detallado de la presencia de estos programas despertador en las redes sociales Facebook y Twitter pone de manifiesto que sólo seis de ellos poseen presencia en ambas plataformas, siendo Facebook la preferida por nueve de cada diez, mientras que Twitter es utilizada por siete.

En función del número de seguidores en Facebook la clasificación de programas quedaría encabezada por "Atrévete", con 529.912 seguidores, que le arrebataría el primer puesto al programa más seguido según el EGM "Anda ya!" (494.588). Seguirían el ranking "Buenos días Javi Nieves" (457.243), "Levántate y Cárdenas" (298.789), "El Gallo Máximo" (121.508 seguidores y que ocupaba el puesto séptimo según el EGM), "El Pirata y su banda" (28.363), "Morning 80" (19.476), "La Mañana de Kiss FM" (16.365) y "El Ahitador" (584 seguidores). Carece de Facebook, tal vez debido a ser el último programa en incorporarse a la franja "Lo Mejor que te pueda pasar", liderado por Nuria Roca.

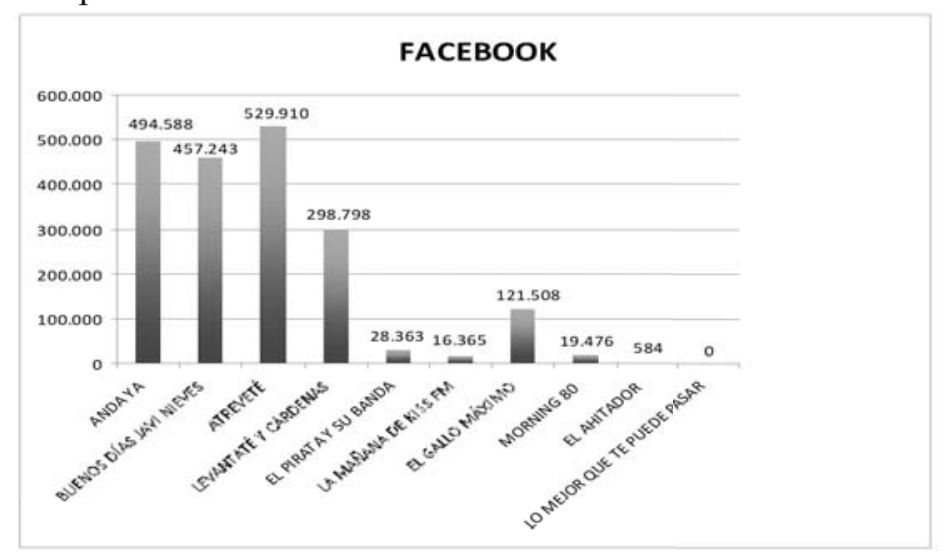

Elaboración propia

El uso de las redes sociales es bastante desigual entre los programas. De hecho, es bastante evidente que mientras que algunos hacen un gran esfuerzo por incrementar el número de seguidores, tal y como lo harían con la audiencia, es el caso de "Levántate y Cárdenas" o "Atrévete", otros como "Morning 80" o "El Ahitador", parece que solo pretenden tener presencia en estos espacios con fines publicitarios.

A efectos cuantitativos hemos realizado un seguimiento de la actividad que estos programas han tenido en Facebook durante la primera quincena del mes de febrero, para ello hemos establecido el nivel de interactividad en base al número de entradas publicadas en el muro de los programas, los comentarios generados en la audiencia, el número de personas que estaban hablando sobre los mismos, así como el tono del lenguaje empleado y el tipo de comunicación (ascendente o descendente) establecido.

En base a estos parámetros, el ranking lo continuarían encabezando "Atrévete" y "Anda ya", seguido por "Levántate y Cárdenas", "Buenos días Javi Nieves" y "La Mañana de Kiss". Todos ellos crearon sus perfiles entre los años 2009 y 2011.

Los dos primeros, curiosamente pertenecientes a la misma emisora, la $S E R$, presentan una interactividad intensa, sus publicaciones diarias oscilan entre las $10 \mathrm{y}$ las 
15 entradas, las cuales suelen tener que ver con el contenido del programa, cosas que envían los oyentes o bien frases célebres, consejos y sentencias curiosas que generan una gran aceptación entre su público y que se traduce en un elevado número de "Me gusta", que pueden llegar a oscilar entre los 600.000 y el millón. De hecho, la mayoría de las entradas que generan comentarios han sido enviadas por los propios oyentes, por lo que la comunicación ascendente es bastante intensa.

La actividad de "Levántate y Cárdenas" y "Buenos días Javi Nieves" es más moderada, sus publicaciones diarias están en torno a las 15 del primero y las 8 del segundo, no obstante, la repercusión entre la audiencia es menor en cuanto a los comentarios generados, que no llegan a la treintena, pese a contabilizar también muchos "Me gusta", sobre los 300.000. Al igual que los dos anteriores, su contenido versa sobre el programa que se está emitiendo y cosas que envían los oyentes.

En un tercer nivel encontraríamos a aquellos Morning Shows cuya interactuación a través de Facebook es escasa, con 3 ó 4 entradas diarias ("El Gallo Máximo" y "El Pirata y su banda") o prácticamente nula ("Morning 80" o "El Ahitador") con 1 ó 2 publicaciones en su muro. Al no haber prácticamente una actualización de contenidos el número de comentarios, "Personas que están hablando de esto" y los "Me gusta" no superan la decena en la mayoría de los casos.

$\mathrm{Si}$ atendemos a la red social Twitter y la presencia que estos programas tienen en ella, debemos decir que sólo dos de los diez tienen no presencia ("Buenos días Javi Nieves" y "El Pirata y su banda"). El resto, poseen perfil y además refuerzan la actividad comunicativa del programa a través de las cuentas personales de presentadores y colaboradores.

En función del número de seguidores, la clasificación quedaría encabezada por “Anda Ya!” (@40Andaya), el programa que también lidera en audiencia real, con 108.151 seguidores. Continúa el ranking, curiosamente "El Gallo Máximo" (@el_gallo_maximo con 52.063), que por audiencia está en séptimo lugar, "Levántate y Cárdenas"(@cardenaseuropa),con 50.818; y “Atrévete" (@atrevetedial),con 36.899 seguidores.

A gran distancia encontramos el resto de programas: "La mañana de Kiss FM"

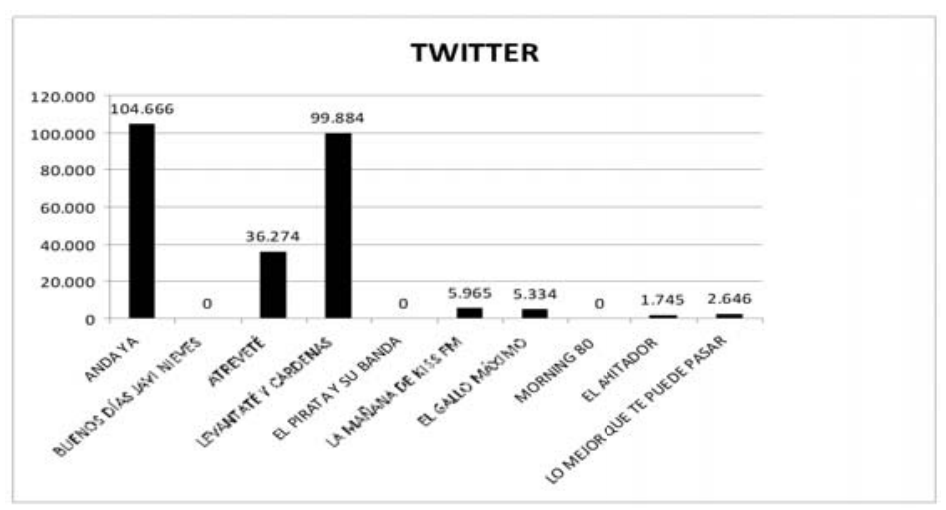

(@lasmananaskiss), con 6.242 seguidores; "Morning 80" (@morning80) con 5.145; "Lo mejor que te puede pasar" (@LoMejorMelodía), con $3.212 \mathrm{y}$ "El Ahitador"(@elahitador) con 2.142 seguidores.

Elaboración propia 
En cuanto a interactividad y frecuencia comunicativa destacan "El Ahitador", con una media de 20 tweets diarios y numerosos retweets y comentarios, "Anda Ya!", con 17; "Atrévete" y "Levántate y Cárdenas", ambos con una frecuencia de entorno a unos 15 tweets diarios. A gran distancia se sitúan el resto de programas, con tan sólo una frecuencia de 3 ó 4 ("La mañana de Kiss FM" y "Lo Mejor que te pueda pasar") y "El Gallo Máximo" y "Morning 80" con tan sólo 1 ó entradas diarias.

La temática de los contenidos suele ser muy similar, por lo general se publican fotos y contenidos multimedia en estrecha relación con el programa, al mismo tiempo retweetean las entradas curiosas que les van entrando de los oyentes y las comentan en antena, se propone a la audiencia que participe y que vayan al Twitter del programa para ver qué está ocurriendo en el estudio de radio, de modo que la interacción es bastante completa, hasta el punto de que los propios locutores y colaboradores interactúan a través de sus propias cuentas con la cuenta oficial del programa y con la audiencia a fin de completar sus informaciones radiofónicas.

En cuanto al tipo de lenguaje utilizado comentar que poco difiere del empleado en las webs y blogs de los programas: se trata de un lenguaje informal destinado a un público con perfil joven.

También son frecuentes las propuestas de hashtags de participación, tal es el caso de \#AtreveteCantizano, \#AndaYaEnlos80, \#lanotisiadeCoco o \#LMQTPP, etiquetas que movilizan comunicativamente a la audiencia y que han llegado a ser Trending Topic, es decir, una de las palabras más repetidas en un momento concreto en Twitter. Este es caso de \#javiercardenas, presentador de "Levántate y Cárdenas" que se convirtió en el tema más comentado del pasado 1 de enero debido a un comentario que realizó sobre las verdades del dominio separatista en Cataluña.

Las cuentas de Twitter también sirven para promocionar los blogs de los programas, las webs de las emisoras, la cuenta en Facebook y los Twitters de los colaboradores y locutores, así como los horarios de emisión, llegándose en ocasiones a proporcionar una información sobre los mismos más completa que la existente en sus propios blogs.

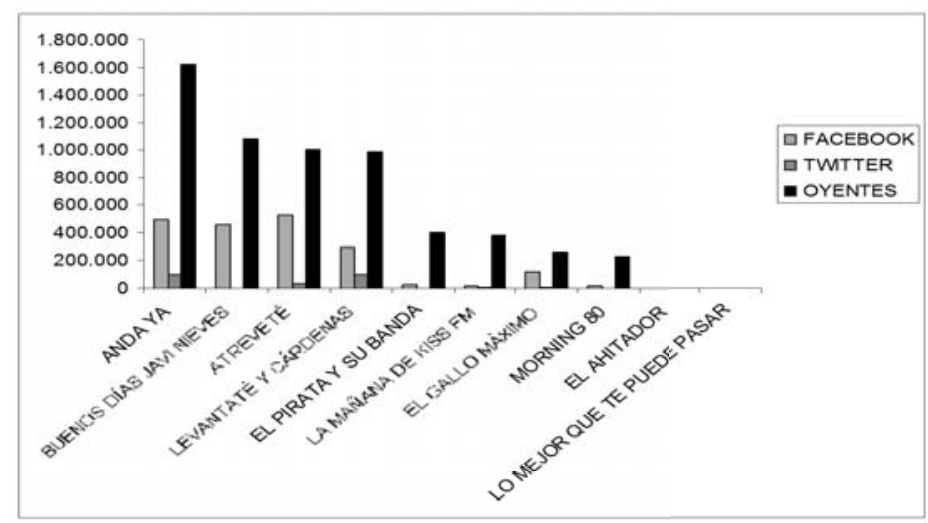

Elaboración propia 


\section{Conclusiones}

Gracias a las herramientas de la Web 2.0 la radio rompe con su concepción instrumental y establece una comunicación plenamente interactiva con una audiencia que deja de ser pasiva y comienza tímidamente convertirse en lo que Cebrián designa como co-creadores incipientes.

En el ámbito de los Morning Shows o programas despertador casi la mitad de la oferta presenta una participación activa a través de blogs, webs, correos electrónicos y redes sociales, creando un nuevo espacio radiofónico en el que se entrecruzan las comunicaciones escritas de los oyentes y usuarios del medio y el flujo radiofónico, de manera que el diálogo y la comunicación de los oyentes se traslada a la antena enriqueciendo el discurso y, en ocasiones, modificando la pauta radiofónica del programa.

El elevado grado de participación del público a través de comentarios demuestra un creciente interés de los programas por abrir conversación con sus oyentes, convirtiéndose en elementos activos de las redes sociales y comunidades que crean, de forma que se mejoran numerosos aspectos del proceso informativo, al tiempo que se potencian las especificidades de las redes sociales, como puede ser el hecho de mejorar la visualización de contenidos a través de los hashtag o etiquetajes que proponen Twitter y Facebook.

El uso de las redes sociales y otros recursos tecnológicos y comunicativos que conforman la Web 2.0 tienen cada vez más penetración en los programas despertador, de forma que estamos asistiendo a un progresivo modelo en el que prima la complementariedad entre la escucha de la radio tradicional y sus nuevos modelos de recepción a través de Internet. No obstante, su uso no es tan extenso y extensivo como en la televisión, donde la audiencia social, al igual que ocurre con la audiencia real, se ha convertido en un indicador de tendencias y una herramienta cada vez más predictiva del éxito, fracaso o evolución de un programa.

\section{Referencias bibliográficas}

ALGUACIL, Sergio (2011): "El itinerario de las noticias: La metamorfosis de la información en Internet". TecCom Studies, n 6. Madrid, pp. 35-47.

ARRESE, Ángel (coordinador, 2003): Empresa informativa y mercados de la comunicación. Estudios en honor del profesor Alfonso Nieto Tamargo. Pamplona, Eunsa, pp. 119-154.

BALSEBRE, Armand (2002): Historia de la radio en España. Madrid, Cátedra.

CASTELLS, Manuel (2009): Comunicación y poder. Madrid, Alianza Editorial.

CEBRIÁN HERREROS, Mariano (2001): La radio en la convergencia multimedia. Barcelona, Gedisa.

CEBRIÁN HERREROS, Mariano (2008): La radio en internet: de la ciberradio a las redes sociales y la radio móvil. Buenos Aires, La Crujía.

CEBRIÁN HERREROS, Mariano (2010): Desarrollos del periodismo en Internet. Zamora, Comunicación Social. 
GALLEGO, José Ignacio (2010): Podcasting. Nuevos modelos de distribución para los contenidos sonoros. Barcelona, Voc Press.

GUTIERREZ. Antonio (2011): "La Radio", en HERRERO, Julio César (ed.): Materiales para la innovación educativa en Estructura de la Comunicación. Madrid, Universitas.

IGLESIAS, Francisco (2004): "Principios e idearios de las empresas radiofónicas", en MARTÍNEZ-COSTA, María Pilar y MORENO MORENO, Elsa: Programación radiofónica. Arte y técnica del diálogo entre la radio y su audiencia. Barcelona, Ariel, pp. 321-345.

KEITH, Michael (2001): "El futuro de la radio en el mercado global”, en MARTÍNEZCOSTA, M ${ }^{a}$ Pilar (ed.): Reinventar la radio. Pamplona, Eunate, pp. 95-105.

KENDEERMAN Max (2008): Marketing experencial. La revolución de las marcas. Madrid, Esic.

LÓPEZ VIDALES, Nereida y ORTIZ SOBRINO, Miguel (20123): Radio 3.0. Una nueva radio para una nueva era. La democratización de los contenidos. Madrid, Fragua.

MORENO, Elsa (2005): "Las «radios» y los modelos de programación radiofónica". Comunicación y Sociedad, vol. XVIII, n ${ }^{\circ}$. Pamplona, Servicio de Publicaciones de la Universidad de Navarra, pp. 61-111.

REQUEJO ALEMÁN, José Luis y HERRERA DAMAS, Susana (2009): “Los nuevos recursos participativos de la Web 1.0 y 2.0 en los portales de las emisoras musicales españolas dirigidas a los jóvenes". Comunicación y hombre; separata del $\mathrm{n}^{\mathrm{o}}$ 5. Madrid, Universidad Francisco de Vitoria, pp. 4-21.

SANABRIA MARTÍN, Francisco (1994): Información audiovisual. Teoría y técnica de la información radiofónica y televisiva. Barcelona, Bosch Comunicación.

TÚÑEZ, Manuel; MARTÍNEZ, Yolanda; y ABEJÓN, Paloma (2010): "Nuevos entornos, nuevas demandas, nuevos periodistas". Estudios sobre el Mensaje Periodístico, vol. 16. Madrid, Servicio de Publicaciones de la Universidad Complutense, pp. 79-94.

VIOLI, Patrizia (2008): "Espacio público y espacio privado en la era de Internet: El caso de los blogs". Cuadernos de Información y Comunicación, vol. 13. Madrid, Servicio de Publicaciones de la Universidad Complutense, pp. 39-59. 